\title{
The role of legal consciousness in the implementation of preparedness for the dangerous driving of road drivers
}

\author{
$1 \mathrm{PhD}$, Associate Professor, Altai State University, Barnaul, Russian Federation. \\ E-mail: kovalenko1288@mail.ru (iD https://orcid.org/0000-0001-6017-8933 \\ $2 \mathrm{PhD}$, Associate Professor, Altai State University, Barnaul, Russian Federation. \\ E-mail: annakuz877@yandex.ru (ID https://orcid.org/0000-0001-5864-7120 \\ 3 Altai State University, Barnaul, Russian Federation. \\ E-mail: kovalenko1288@mail.ru (D) https://orcid.org/0000-0003-4961-9480
}

\author{
Kseniya E. Kovalenko ${ }^{1}$ \\ Anna S. Kuzmina ${ }^{2}$ \\ Nataliya E. Kovalenko ${ }^{3}$
}

ABSTRACT: The article discusses the role of legal consciousness in enhancing the internal factors of preparedness for dangerous driving. The analysis of statistical data regarding traffic accidents is given. The external and internal predictors of dangerous driving are analyzed. The results of an empirical study showing the relationship of the style of driving a vehicle and the development of the legal consciousness of road users are discussed.

Keywords: Dangerous driving. Legal awareness. Traffic safety. Traffic accidents.

\section{INTRODUCTION}

Over the past decades, interest in solving problems in the field of traffic and improving safety has been growing in the world community. In September 2015, the heads of state gathered at the United Nations General Assembly adopted the historic Sustainable Development Goals (SDGs). One of the new challenges under SDG is to halve by 2020 the number of deaths and injuries resulting from road traffic accidents (RTAs). Setting such an ambitious goal of reducing mortality as a result of preventing traffic accidents is an important step towards improving road safety.

Accidents are among the leading causes of injuries and deaths globally. According to the Pulitzer Center, the total number of deaths on world roads has reached 1 million 240 thousand deaths per year, and, unfortunately, there is every chance to triple the number to 3.6 million per year by 2030 .

In developing countries, road deaths have become the fifth leading cause of death, among such causes as HIV / AIDS, malaria, tuberculosis, etc. Poor countries account for $50 \%$ of the world's traffic, but $90 \%$ of deaths. According to Jose Luis Yrigoyen, an expert on road safety at the World Bank, road deaths are also "a problem causing poverty, as road accidents cost an average of $1 \%$ to $3 \%$ of a particular country's GDP.

High mortality rates on roads in most cases are due to subjective factors: frivolity of road users, unreasonably risky maneuvering, violation of traffic rules, poor functional condition of drivers, etc. The above factors indicate the relevance of studying approaches that help minimize accidents.

The system of ensuring road safety, according to many scientists, consists of a combination of elements: the degree of development of road transport networks; structure and volume of traffic flows; technical condition of the fleet of vehicles; qualifications and discipline of drivers and personnel; moral and ethical standards of road users; legislative base and system of enforcement of laws and regu- 
lations; properties of technical, organizational and information systems. Conventionally, the above factors can be divided into four clusters:

\# regulatory and legal framework; technical, organizational and information systems;

* medical care system; legal culture of road users.

In the framework of this article, the issue of the formation of a legal culture of safety of road users in the Russian Federation and foreign countries will be considered.

Currently, a conceptual apparatus of scientific analysis of the social aspects of road safety has been formed. The generic definition of the degree of road safety is "transport safety". Transport safety is a state of national transport systems, which is provided with organizational, technical, financial, regulatory measures and allows to prevent accident rate as much as possible.

Road safety as one of the components of transport security is understood as the state of protection from dangers and threats that can cause irreparable harm (damage) to the vital human interests. The components of this definition are: general understanding of road safety; responsibility of road users to safety requirements; abilities that ensure safe behavior on the road.

An interpretation of the concept of "culture of safe behavior on the road" seems theoretically important in this context. To date, the concept of "safety culture" in Russian and foreign literature can be considered established. However, the issue of semantic content is debatable. V. N. Moshkin defines the upbringing of a personal safety culture as the preparation of a pupil for the prevention and overcoming of harmful and dangerous factors of life. The culture of life safety, as defined by T. V. Melnikova, is understood as a way of organizing human activity, presented in the system of social norms, beliefs, values, ensur- ing the preservation of his life, health and integrity of the world. In our perception, the legal culture of safety of road users is understood as a combination of knowledge, skills, abilities and value-behavioral attitudes of road users aimed at minimizing emergency situations on the road.

On June 8, 2016, in paragraph 2.7 of the Rules of the Road, the concept of "dangerous driving" was introduced, which is synonymous with the concept of "high risk driving", which is used more often in foreign psychological literature. The introduction of this term served as an impetus for the development of the concept of "dangerous driving" at an interdisciplinary level. At this stage of studying this problem, both external and internal factors are predictors that provide the probability of being prepared for dangerous driving.

Among the external predictors that determine the willingness to reproduce dangerous driving, usually indicate weather conditions (poor visibility, blizzard, thunderstorm, hurricanes, wind, etc.), quality of road surface, time of day of driving, distracting factors (for example, use of a mobile phone.) (V.G. Bulygina, A.A. Dubinsky, S.V. Shport, D.S. Kalinkin). However, as a number of studies show, the impact of external predictors becomes the most significant conditions in the updating of internal parameters associated with subjective traffic. So, driving a vehicle in conditions of poor visibility is complicated by some stylistic characteristics of the driver, for example, a tendency to exceed the speed limit, the need to experience a thrill when driving at high speed, impatience while driving, aggressiveness, etc. This is of particular importance for drivers with a low level of legal awareness. As a number of studies show, the key mechanism that triggers the behavior of road users is the right consciousness. The right consciousness of road users determines the implementation of the rule of law and makes it possible to implement certain internal factors that en- 
sure willingness or resistance to the implementation of dangerous driving on the road.

\section{DEVELOPMENT}

Determining the relationship of the level of legal consciousness of road users with vehicle driving styles.

According to Khudoykina T.V. legal consciousness can be evaluated as a single whole and in its component parts: legal knowledge (legal awareness) and attitude to legal phenomena. Empirical indicators of legal consciousness in this case are knowledge of law and a positive attitude towards compliance with legal norms. In the studies of Shegortsov V.A. In the analysis of legal consciousness, attention is focused primarily on assessing the type of attitude to the requirements of specific legal norms, the conviction of the need to comply with laws, and then on assessing the volume and content of legal knowledge.

In the Decree of the Government of the Russian Federation of October 3, 2013 N 864 Moscow "On the federal target program" Improving road safety in 2013 - 2020 ", the priority tasks for ensuring safe traffic are: creating a system of propaganda impact on the population with the aim the formation of a negative attitude to offenses in the field of traffic; the formation of safe road behavior in children; improving driving culture.

At the first stage (2013-2015) of the implementation of the Program for teaching preschool and school-age children the skills of safe behavior on the road, 17 mobile car camps, 1725 pieces of equipment allowing to develop these skills in a game form, and more than 2.8 million reflective units were delivered devices for distribution among the specified category of minors. This indicates the purposeful formation of a legal safety culture in young children. It seems necessary to lay the foundation for the positive upbringing of the younger generation and teaching them the rules of the road, since at this stage important processes of socialization are taking place. Depending on what idea of traffic will be established, a legal safety culture will be developed for many years.

Another factor that positively affects the formation of a legal safety culture among drivers is the preparation for driving. During 2013-2015, serious steps were taken in the Russian Federation to improve the regulatory framework governing the training of drivers and their receipt of a driver's license. Thus, the adoption of a list of training and retraining programs for vehicle drivers and the approval of a new procedure for admitting to driving means evidence of increased attention to graduates of driving schools and the skills gained from their training. The programs increased the number of hours devoted to practical training of candidates for drivers, and the requirements for final tests were complicated.

Speaking about the legal culture of drivers of vehicles, it is worth mentioning a study conducted in 2013 on the basis of the Orel Law Institute of the Ministry of Internal Affairs of Russia named after V.V. Lukyanchenko. The types of drivers that violate traffic rules were identified: a cynical driver (there is experience of impunity for committed traffic offenses); provocative driver (creates conditions for other offenders to commit an offense); aggressive - risky driver (creates conflict situations, prone to reckless actions); inexperienced driver (has a low level of car ownership); emotionally unstable driver (anxious, amenable to fear and stress on the road).

In most countries, public policies are reflected in national accident reduction programs, setting deadlines for specific activities and allocating appropriate resources. National road safety programs operate in Australia, Bulgaria, Great Britain, Germany, Italy, Canada, Latvia, Lithuania, Portugal, Turkey, Finland, Japan. In some countries, special programs are adopted in addition to national pro- 
grams. All measures, directly or indirectly, are aimed at the formation of the legal culture of road users. As specific examples will be considered: Germany, the Netherlands, Finland, Japan.

In Germany, the area of safe road traffic is regulated by the Law on Road Safety, the Law on Violations of the Rules of the Road, and the Code of Provisions on Road Traffic. The system of road fines is set out in the Fines Catalog. High fines are mainly the main deterrent from violation of traffic rules. A number of scholars have noted a high legal culture among road users. This is due to the following facts.

Firstly, according to German laws, drivers are required to undergo medical and psychological examinations. During the examination, medical workers and psychologists decide on the psychological ability of a person to safely drive a car. Without an approval, getting a driver's license is not possible.

Secondly, high fines act as a deterrent from traffic violations. In the year from fines in the treasury of Germany comes 30 million euros (driving while intoxicated up to 3 thousand euros).

Thirdly, Germany has the most polite drivers. According to ADAC (a car club for protecting motorists' rights), even the "most harmless" harsh statement costs at least 250 euros. The courts impose such a fine on the words "touched," "nuts," "idiots." If such actions are committed against a policeman, one of whose duties was to impose fines for improper parking, then the punishment increases in arithmetic sequence ("bandit from the high road" - 450 euros, "rabble roadside" - 900 euros, "idol" or "pig" in uniform "1000 euros," doodle in the uniform "- 1500 euros).

Fourth, effective preventive measures. The police work according to the following model: stop the traffic violator, conduct an explanatory conversation, show a fine, provide the necessary information, the required level of knowledge.

Fifth, the widespread promotion of safe traffic. Work on the promotion of road safety is carried out for all road users. Target groups were defined: kindergarten, schoolchildren, students, elderly people. Depending on the level of perception of the surrounding reality, consultations, lectures, and classes on road safety are developed by specially trained specialists in road safety.

The World Health Organization (WHO) calls the Netherlands one of the most successful in the world in road safety. The Netherlands is one of the first places in the world for road safety. The mortality rate in accidents is twice as low as the European average.

It is important to equip drivers who were held accountable for driving while intoxicated with such a penal measure as equipping an automobile with an alcohol lock.

Educational work on the development of a legal safety culture for road users is not carried out, as the Dutch authorities believe that this is not enough to solve problems in the field of traffic, but specific measures are needed. But this does not affect the high level of legal culture prevailing in the Netherlands.

\section{RESULT.}

The study involved respondents who went through an anonymous survey through filling out Google forms. The sample included men (208) and women (251), with different driving experience from 1 year to 15 years and driving a car from 1 to 8 hours per day.

Readiness for dangerous driving was quantified through the indicator "Number of fines per year for violation of traffic rules".

To study the development of legal consciousness, subjects were asked to evaluate their legal awareness, understood as a level of knowledge in the field of traffic rules on a 
scale of 1 to 5 (1 - low level, 5 - high level) and attitude to legal phenomena, understood as positive installation to compliance with legal norms. Attitude to legal phenomena was evaluated as the degree of agreement on a scale of 1 to 5 (1 - complete disagreement, 5 complete agreement with the statement with the statement "Compliance with the law is mandatory for everyone."

To assess the driving style of the vehicle, the Multidimensional driving style inventory (MDSI) methodology (multidimensional driving style questionnaire), adapted in Russian, was used.

The English-language questionnaire included 45 questions grouped into 5 factors:

Factor 1 "Aggressive Driving"

Factor 2 "Risky Driving"

Factor 3 "Disturbing Driving"

Factor 4 "Unsustainable Driving"

Factor 5 "Careful driving"

The procedure for testing the Russian version of the questionnaire consisted of a number of stages:

- the questionnaire in its original version of the text was translated from English;

- the text of the methodology was compiled in Russian, ambiguous and difficult to understand statements were identified and reformulated;

- data was collected to evaluate the psychometric indicators of the questionnaire: indicators of descriptive statistics, the reliability and consistency of the items, the retest reliability and the structure of the method scales (based on correlation, exploratory and confirmatory factor analysis) were revealed;

- Converged validity of the methodology was evaluated.

As a result of the procedures, the factor structure of the questionnaire was saved in the original version.

Methods of mathematical data processing: regression analysis, Spearman correlation analysis. The reliability of the results was eval- uated at $\mathrm{p}<0.05$. Processing was carried out using the statistical package SPSS 23.0.

At the first stage of the study, indicators of legal awareness of road users were analyzed. An analysis of the results showed that road users highly appreciate their knowledge of the rules of the road (4.058), and their attitude to compliance with legal norms is somewhat lower (3.41).

To identify the relationship between legal awareness and attitude to legal phenomena, Spearman's correlation analysis was applied. No reliable relationship between the parameters was found $(\mathrm{r}=0.33 ; \mathrm{p}=0.08)$. Knowledge of legal norms does not always determine the willingness of road users to comply with them. Such a contradiction in the minds of road users gives rise to offenses on the roads and creates the basis for traffic accidents.

In addition, a regression analysis was used to identify the effect of legal consciousness on the risks of reproduction of dangerous driving. Using regression analysis, it was revealed that a positive attitude towards legal norms reduces the likelihood of dangerous driving, expressed in the number of fines for violating traffic rules.

The higher the level of a positive attitude towards legal norms, the less fines road users receive for violating traffic rules $(R \wedge 2=$ 0.236, $p=0.02, \beta=-0.23)$.

At the next stage of the study, the relationship of vehicle driving styles with readiness for dangerous driving was revealed.

A positive correlation was obtained between the hazardous driving preparedness parameter and the Aggressive Driving scale ( $\mathrm{r}$ $=0.83 ; \mathrm{p}=0.01)$, Risky Driving $(\mathrm{r}=0.73 ; \mathrm{p}=$ $0.01)$, and Unstable Driving " $(\mathrm{R}=0.49 ; \mathrm{p}=$ $0.05)$.

Aggressive driving, signals to other drivers, reducing the distance with other drivers, the need for risk, thrills on the road, deliberate violation of the law, lack of a plan on the road 
increases the likelihood of traffic accidents, reducing the safety of other road users.

Thus, systemic interdisciplinary studies of the role of legal consciousness in ensuring the safety of road users are promising and require further study.

\section{CONCLUSION}

Thus, the formation of a legal safety culture for road users is influenced by the policy pursued in the country, the normative fixation of traffic rules, the level of penalties, mentality, especially the worldview, contact between law enforcement agencies and the public, educational work, and a system of measures for prevention and prevention offenses on the road.

The promotion of culture and road safety should be one of the most important directions in the politics of all states. This requires the creation of an information field that provides a high level of social, legal, political, psychological and pedagogical impact on road users. In such a work, the main emphasis should be placed on people understanding their common and personal interest in solving the problem, on the need for reasonable, responsible, cultural, mutually respectful and disciplined behavior on the roads, and the attention of road users to each other.

The search for new opportunities to enhance road safety work needs to be encouraged. It is impossible to completely eliminate accidents, but there is a real possibility of reducing the number and specific indicators of serious injuries and deaths in a short period of time. It is worth focusing on key risk factors, wider and more effective implementation of safety principles and measures and the formation of a positive legal safety culture among road users who have proven their effectiveness in different countries.

\section{REFERENCES}

BRAZHNIK, F.S. Some topical issues of qualification of receiving a bribe. Criminal law. 2000, 1.

BULYGINA, V.G., DUBINSKY, A.A., SHPORT, S.V., KALINKIN, D.S. Psychology of high-risk driving (review of foreign studies). Psychology and Law. 2016, 6(2). https:// doi.org/10.17759/psylaw.2016060206

DINEKA, V.I. Official crimes under the criminal law of Russia. Stavropol, 1999.

DULA, C.S., GELLER, E.S. Risky, aggressive, or emotional driving: Addressing the need for consistent communication in research. Journal of Safety Research. 2003, 34. https://doi.org/10.1016/i.jsr.2003.03.004

FARBEROVA, L.I. Illegal granting of property right as a subject of bribery. Jurisprudence and law enforcement practice. 2014, 1 (27). FARBEROVA, L.I. Receiving a bribe in the form of money: a criminal law characteristic and qualification issues. Bulletin of the Tyumen Institute for Advanced Studies of the Ministry of Internal Affairs of Russia. 2013, 1.

GOUVIER, W. D., MAXFIELD, M.W., SCHWEITZER, J.R., HORTON, C.R. SHIPP, M., NEILSON K., HALE, P. Psychometric prediction of driving performance among the disabled. Archives of Physical Medicine and Rehabilitation. 1989, 70.

HILYUTA, V.V. Counterfeit money as a subject of bribery. Legality. 2017, 5.

IVANOV, N. To the discussion of clarifications of the Plenum of the Supreme Court on the qualifications of bribery. Criminal law. 2013, 5.

KACHALOV, V.V. The terminology of criminology: problems and development prospects. Bulletin of the Moscow University of the Ministry of Internal Affairs of Russia. 2014, 14.

KHUDOYKINA, T.V. Technology of evaluation and measurement of legal conscious- 
ness. Theory and practice of social development. 2015, 21.

KLEPITSKY, I.A. Receiving a bribe in the criminal law of Russia. Commentary on legislation. Moscow, 2001.

KOVALENKO, K. E., ROZENTSVAIG, A. I., GUBAREVA, A.V. International terrorism and international cyberterrorism. Quidinvestigacion ciencia y tecnologia. 2018, 2 (SI).

KRASNOPEEVA, E. V. The subject of a bribe and the qualification of the deed. Legality. 2001, No. 8.

ODENHEIMER, G. L., BEAUDET, M., JETTE, A. M., ALBERT, M. S., GRANDE, L., MINAKER, K. L. Performance based driving evaluation of the elderly driver: safety, reliability, and validity. Journal of Gerontology. 1994, 49 (4). https://doi.org/10.1093/geronj/ 49.4.M153

SHARAPOV, R. D. Money, securities and other property as a subject of a bribe: criminal law characteristics and qualification issues. Academic Bulletin. 2003, 1.

SITKOVETS, O. N. Responsibility for receiving and giving a bribe. Russian investigator. 2005, 1.

VDOVIN, R. A., ROZENTSVAIG, A. I., KOVALENKO, K. E., Kovalenko, N. E. Defects of terminology in law and technique. Religacion-revista de ciencias sociales y humanidades. 2019, 4(18) SI.

VOLZHENKIN, B.V. Official crimes. Moscow, 2000.

YANI, P.S. Qualification issues of bribery. Legality. 2013, 3.

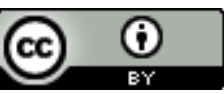

License information: This is an openaccess article distributed under the terms of the Creative Commons Attribution License, which permits unrestricted use, distribution, and reproduction in any medium, provided the original work is properly cited.
Article received on November 10, 2019.

Evaluated November 15, 2019.

Accepted on November 15, 2019.

Published on November 21, 2019.

How cite this article (ABNT):

KOVALENKO, Kseniya E.; KUZMINA, Anna S.; KOVALENKO, Nataliya E. The role of legal consciousness in the implementation of preparedness for the dangerous driving of road drivers. Estação Científica (UNIFAP), Macapá, v. 9, n. 2, p. 63-69, apr./jun. 2019. 